\title{
Histopathological analysis of tumours and tumour-like lesions of colon and rectum
}

\author{
Pramila Vaidhya ${ }^{1,2}$, Ram Chandra Adhikari ${ }^{1}$, Anil Dev Pant ${ }^{1}$ \\ ${ }^{1}$ Department of Pathology, Institute of Medicine, Tribhuvan University Teaching Hospital, Kathmandu, Nepal \\ ${ }^{2}$ Department of Pathology, Sumeru Hospital, Dhapakhel, Lalitpur, Nepal
}

\author{
Keywords: \\ Colon; \\ Rectum; \\ Tumours; \\ Tumour like lesion;
}

\begin{abstract}
Background: Tumours and tumour like lesions of the colon and rectum have overlapping clinical presentation and may be difficult to diagnose on clinical grounds alone. Histopathological examination although helpful to arrive at correct diagnosis, at times may be difficult and may require ancillary tests such as immunohistochemistry.
\end{abstract}

Materials and Methods: A prospective cross sectional study enrolled 125 cases of colorectal biopsies after histopathological confirmation of tumours and tumour like lesions. The specimens were received at the Department of Pathology, of TUTH, from December 1, 2015 to November 30, 2016.

Results: Out of 125 cases, 32 cases were benign tumours, 36 cases were malignant tumours and 57 cases were tumour like lesions. Most common age range was 51-60 years with mean age of 38 years. Males comprised $76.74 \%$ and females $23.26 \%$ with ratio of $3: 1$. Juvenile polyp was the commonest lesion. Among benign tumours, tubular adenoma was the most common (19.2\%), adenocarcinoma was most common malignant tumour (25.6\%) and juvenile polyp was the most common tumour like lesion (27.2\%). Left side was most common side (66.67\%) and rectum was the most common site (48.8\%).

Conclusions: The commonest indications for colorectal biopsies were tumours and tumour like lesions. Juvenile polyp was the most common tumour like lesion, tubular adenoma was the most common benign tumour and adenocarcinoma was the most common malignant tumour. Histopathological examination is a gold standard for confirmation of all tumour and tumours like lesions of colon and rectum.

\section{Correspondence:}

Dr. Pramila Vaidhya, $M D$

Department of Pathology,

Sumeru Hospital, Dhapakhel, Lalitpur, Nepal

ORCID ID:0000-0002-4191-4103

Email:rudras_ckem@yahoo.com

Received : February $21^{\text {st }} 2020$; Accepted : March $24^{\text {th }} 2020$

Citation: Vaidhya P, Adhikari RC, Pant AD. Histopathological analysis of tumours and tumour-like lesions of colon and rectum. JPN 2020;10:1654-8 DOI: 10.3126/jpn.v10i1.28747

Copyright: This is an open-access article distributed under the terms of the Creative Commons Attribution 4.0 International License, which permits unrestricted use, distribution, and reproduction in any medium, provided the original author and source are credited.

\section{INTRODUCTION}

Colon is the terminal part of gastrointestinal tract and its lesions accounts for large number of human pathology. ${ }^{1}$ For the evaluation of various colon and rectum disorders colonoscopy is widely used. The most common lesions of colon and rectum are infectious and inflammatory lesions, congenital disorders, various benign and malignant tumours and tumour like lesions. Colorectal tumours can be benign and malignant. More than $90 \%$ of colorectal carcinomas are adenocarcinomas originating from epithelial cells of the colorectal mucosa. ${ }^{2}$ Various tumour-like lesions and benign tumour may arise as polyp in colon and rectum. Colorectal 
polyps may also be histologically classified as neoplastic or as non-neoplastic (hyperplastic, hamartomatous, or inflammatory). ${ }^{3}$ Benign colorectal tumours comprise of adenomas, benign mesenchymal tumours like lipoma, leiomyoma, hemagiomas. ${ }^{4}$ The adenomatous polyp of the colon and rectum and its possible relationship to carcinoma has been the subject of much speculation thus worthy of special attention. ${ }^{5}$ The goals of colonoscopic surveillance in patients with adenomas are to prevent interval cancers and reduce colorectal-cancer mortality. ${ }^{6}$ Tumour like lesion basically consists of various polyps. Juvenile polyp are most frequently diagnosed tumour like lesion which is most common in the first 10 years of life, with a peak age of diagnosis between two and five years of age ${ }^{7}$, but it can be seen in adult and rarely in elderly people. Tumour and tumour like lesions of colon and rectum may present with various clinical features like per rectal bleeding, weight loss, distension of abdomen and diarrhea. ${ }^{8}$ This study is undertaken to evaluate the prevalence of various tumour and tumour like lesions of colon and rectum and their distributions according to the age, sex and site. In addition to it, attempt is also made to study clinical presentation, correlation with colonoscopic and histomorphological features of various tumour and tumour like lesions of colon and rectum.

\section{MATERIALS AND METHODS}

This is a prospective cross sectional hospital based study which enrolled 125 cases of colorectal biopsies after histopathological confirmation of tumours and tumour like lesions. Ethical clearance was obtained from the Intuitional review committee. The specimens were received at the Department of Pathology, of TUTH, from December 1, 2015 to November 30, 2016 after obtaining consent, detailed clinical and endoscopic information. Specimens were fixed

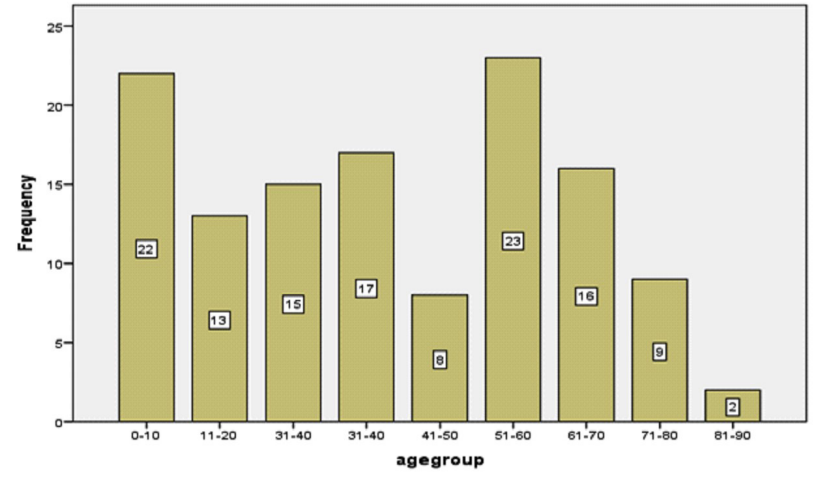

Figure 1: Bar diagram showing age range of patient.

in $10 \%$ formalin and subjected for tissue processing, and H\&E sections were studied. The data were entered and analysed in EXCEL.

\section{RESULTS}

Out of 125 cases received at the Department of Pathology, of TUTH, from December 1, 2015 to November 30, 2016, 32 cases were benign tumours, 36 cases were malignant tumours and 57 cases were tumour like lesions.

Most common age group of the patient enrolled in the study was 51-60 years (fig. 1). The mean age of the patient was 38.41 years with median age of 37 years. There was male predominance for tumour and tumour like lesion $(76.74 \%$ vs $23.26 \%$ ) with male to female ratio of $3: 1$. Histological diagnoses of tumour and tumour like lesion are shown in table 1 .

Juvenile polyp was the commonest histopathological

Table 1: Frequency of different lesions according to histopathological diagnosis of tumour and tumour like lesion.

\begin{tabular}{lcc}
\hline Histopathological diagnosis & Number & Percent (\%) \\
Juvenile polyp & 34 & 27.2 \\
Hyperplastic polyp & 7 & 5.6 \\
Tubular adenoma & 24 & 19.2 \\
Tubulovillous adenoma & 7 & 5.6 \\
Carcinoma & 32 & 25.6 \\
DLBCL & 1 & 0.8 \\
GIST & 1 & 0.8 \\
Inflammatory myofibroblastic tumour & 1 & 0.8 \\
\hline Inflammatory polyp & 11 & 8.8 \\
Juvenile polyposis coli & 2 & 1.6 \\
\hline Lymphoid polyp & 2 & 1.6 \\
\hline Non Hodgkin lymphoma & 1 & 0.8 \\
\hline Peutz jeghar polyp & 1 & 0.8 \\
\hline Submucosal lipoma & 1 & 0.8 \\
\hline Total & $\mathbf{1 2 5}$ \\
\hline
\end{tabular}


Table 2: Sitewise distribution of tumours and tumour like lesions.

\begin{tabular}{lcc}
\hline Site & Number & Percent (\%) \\
Caecum & 14 & 11.2 \\
Hepatic flexure & 2 & 1.6 \\
Transverse colon & 6 & 4.8 \\
Ascending colon & 12 & 9.6 \\
\hline Descending colon & 3 & 2.4 \\
\hline Sigmoid colon & 22 & 17.6 \\
\hline Rectum & 61 & 48.8 \\
\hline Rectosigmoid & 2 & 1.6 \\
\hline Colon & 1 & .8 \\
\hline splenic flexure & 2 & 1.6 \\
\hline Total & $\mathbf{1 2 5}$ & $\mathbf{1 0 0 . 0}$ \\
\hline
\end{tabular}

diagnosis inclusive of both tumours and tumour like lesions. Among benign tumours, tubular adenoma was the commonest with a total of 24 cases (19.2\%), adenocarcinoma was the commonest malignant tumour with a total 32 cases $(25.6 \%)$ with moderately differentiated adenocarcinoma being the most common histological subtype, accounting $47 \%$ of total adenocarcinoma and juvenile polyp was the commonest tumour like lesion accounting total 34 cases (27.2\%). Most common side was left side of colon accounting for $66.67 \%$ in comparison to right side of colon which accounted for $33.33 \%$. Rectum was the most common site for tumours and tumour like lesions accounting for 61 cases (48.8\%) shown in table 2.

Among the total 125 cases studied colonoscopic diagnosis was available in total 81 cases. Most common colonoscopic diagnosis was polyp accounting for 51 cases (63\%) followed by carcinoma accounting for 21 cases $(26 \%)$. Correlation of colonoscopic diagnosis with histopathological diagnosis is given in Table 3. There was one case of familial adenomatous polyposis who presented with more than 100 polyps throughout colon and rectum.

\section{DISCUSSION}

In the present study, youngest patient was 2 years and the oldest was 84 years old. The most common age group involved was 51-60. The mean age was 38.41 years and median age was 37 years.

In this study, juvenile polyp was the most common tumour like lesion. The most common age group for juvenile polyp in this study was $0-10$ years. The youngest patient was 2 years and the oldest was 68 years. According to the study done by Zuber et al. ${ }^{9}$, juvenile polyp was most common tumour like lesion and the most common age group was from 0-10 years which correlates with the present study. According to the study done by Lee B et al. ${ }^{10}$ The mean age of the patients with juvenile polyp was 6.5 years with age range of 1.3-14.5 year which corresponds to the present study.

Most common age group for the benign tumour was 51-60 years and tubular adenoma was the most common benign tumour. The youngest patient in present study was 24 years and oldest patient was 71 years. The mean age was 50.31 years. Similar study was done by Corley et al. ${ }^{11}$, in which adenomas were most common benign lesion and the most common group was 50-54 years similar to the present study. In the present study, most common malignant tumour was adenocarcinoma. It was most common in age group between 51-60 years. The youngest patient was 16 years and the oldest was 84 years, and the mean age was 51.80 years. In similar study done by Hussain et al. ${ }^{12}$, the mean age was 55.8 years as in present study adenocarcinoma was most prevalent malignant tumour. The youngest patient with an adenocarcinoma was 18 years of age and the oldest patient was 80 years of age.

Male patients accounted for $76.74 \%$ and females accounted for $23.26 \%$ with the ratio of $3: 1$ showing male predominance

Table 3: Correlation of colonoscopic diagnosis with histopathological diagnosis

\begin{tabular}{|c|c|c|}
\hline COLONOSCOPIC DIAGNOSIS & $\begin{array}{l}\text { HISTOPATHOLOGICAL DIAG- } \\
\text { NOSIS }\end{array}$ & Total number \\
\hline \multirow{7}{*}{$\operatorname{POLYP}(\mathrm{n}=51)$} & Juvenile polyp & 25 \\
\hline & Hyperplastic polyp & 4 \\
\hline & Inflammatory polyp & 6 \\
\hline & Tubular adenoma & 10 \\
\hline & Tubulovillous adenoma & 4 \\
\hline & Lymphoid polyp & 1 \\
\hline & Juvenile polyposis & 1 \\
\hline \multirow{2}{*}{ Carcinoma(ulceroproliferative and exophytic growth) $(n=26)$} & Adenocarcinoma & 24 \\
\hline & Tubular adenoma & 2 \\
\hline Caecal mass $(n=1)$ & GIST & 1 \\
\hline Ileocecal Tuberculosis $(n=1)$ & Adenocarcinoma & 1 \\
\hline Inflammatory lesion $(\mathrm{n}=1)$ & Inflammatory myofibroblastic tumour & 1 \\
\hline Adenomatous polyposis coli $(n=1)$ & Juvenile polyposis coli & 1 \\
\hline
\end{tabular}


than female in this study. According to Mubeen et al. ${ }^{13}$, male population was more predominant than female with the ratio of $1.5: 1$. Both benign and malignant tumours were more common in male, than in female correlating with the study done by Tung et al. ${ }^{14}$ with the male to female ratio being 1.5:1. In another study done by Eshghi et al. ${ }^{17}$ in benign lesions, 716 patients records were reviewed, 437 patients (61\%) were males and 279 (39\%) were females.

In this study, left side of the colon was the most common side and rectum was the most common site for tumour and tumour like lesions. It comprises $61 \%$ of tumour like lesion, $41 \%$ of benign tumours and $25 \%$ of malignant tumours. According to Roth et al. ${ }^{15}$, rectum was the most common site for tumour like lesion accounting for $72 \%$ correlating with the present study. In the study done by Mubeen et al. ${ }^{13}$, left side of colon was the commonest side and rectum was the most common affected site for adenocarcinoma constituting about $40.14 \%$ cases, correlating with the present study.

In this present study in total of 125 cases of histologically diagnosed tumour and tumour like lesions of colon and rectum, juvenile polyp was the most common histological diagnosis accounting for a total 34 cases $(27.2 \%)$ followed by adenocarcinoma 32 cases $(25.6 \%)$ and tubular adenoma 24 cases $(19.2 \%)$. Similarly again juvenile polyp was the most common tumour like lesion diagnosed in total 34 cases (26.4\%). A study done by Corley et al. ${ }^{11}$ also had juvenile polyp as the most common tumour like lesion comprising of 100 cases $(65.78 \%)$. In present study, most common benign tumour was tubular adenoma with a total of 24 cases $19.2 \%$ of total tumor and tumour like lesions and $75 \%$ of total benign tumours. Similar study was done by Shussman et al. ${ }^{3}$, in which adenomatous polyp was the most common benign tumour occurring in $20-40 \%$ of screening colonoscopies and tubular adenoma was the most common histological subtype, constituting approximately $65-80 \%$ of all polyps removed. In the current study, most common malignant tumour was adenocarcinoma accounting for 32 cases $(24.8 \%)$ of total cases of tumours and tumour like lesion and $89 \%$ of total malignant tumours. Moderately differentiated adenocarinoma was the most common histological type of adenocarcinoma accounting $47 \%$ of total adenocarcinoma. Similar study was done by Mubeen et al. ${ }^{13}$, in which the predominant malignant tumors was adenocarcinoma constituting 439 cases $(98.43 \%)$ of which moderately differentiated type adenocarcinoma was seen in 224 cases $(50.24 \%)$.

In this study, out of 125 cases only 81 cases were provided with colonoscopic diagnosis out of which polyp was the most common diagnosis accounting 51cases (63\%) of which juvenile polyps accounted for 25 cases. In the similar study done by Betes et al. ${ }^{16}$, polyp was most common colonoscopic diagnosis. In their study out of 2210 cases 825 cases $(37.3 \%)$ were polyps and tubular adenoma was most common finding accounting 516 cases (23.3\%). Tubular adenoma was the most common pathological type, occurring in 181 patients $(47.8 \%)$, followed by tubulovillous adenoma (14.2\%). In the colonoscopic study done by Eshgi et al. ${ }^{17}$, 437 patients (61\%) were male and $279(39 \%)$ were females. The mean patient age was 55.3 years and the frequent age group was 18-89.

In this study there was one case (21 years female) with colonoscopic diagnosis of adenomatous polyposis coli which presented with $>100$ polyps in colorectal region. These polyps were histologically confirmed as juvenile polyposis coli. According to Tam et al. ${ }^{18}$, juvenile polyposis coli was more common in females and is most common in first two decades of life, with mean age at diagnosis being 18.5 years.

\section{CONCLUSIONS}

Biopsies of tumours and tumour like lesions of colon and rectum constituted majority of total number of colorectal biopsies. The present study had also attempted to correlate the colonoscopic findings of colorectal lesions with their histopathological diagnosis. Patients on their fifth to sixth decade constituted the most common age with male predominance. Tumour like lesions were most common lesion observed and rectum was the commonest location. Juvenile polyp was the commonest tumour like lesion, tubular adenoma was most common benign tumour and adenocarcinoma was most common malignant tumour. Histopathological examination is gold standard for confirmation of the diagnosis of various tumours and tumour like lesions and hence aid in guidance for the treatment and management.

\section{Conflict of interest: None}

\section{REFERENCES}

1. SS. Large Intestine, in Gray's Anatomy anatomic basis of clinical practice., H.J. Borley R, Editor. 2008, Elsevier. p. 1177-1205.

2. Strum WB. Colorectal Adenomas. N Engl J Med, 2016. 374(11):106575. Crossref

3. Shussman N, Wexner SD. Colorectal polyps and polyposis syndromes. Gastroenterol Rep (Oxf), 2014. 2(1):1-15. Crossref

4. JR. Large Bowel, in Rosai and Ackerman Surgical pathology, S. Louis, Editor. 2012, Elsevier: Missouri. p. 731-774.

5. Blatt LJ. Polyps of the colon and rectum. Diseases of the Colon \& Rectum, 1961;4(4): 277-82.

6. Bonnington SN, Rutter MD. Surveillance of colonic polyps: Are we getting it right? 2016; 22(6):1925-34. Crossref

7. Silverberg SG. "Juvenile" retention polyps of the colon and rectum. The American Journal of Digestive Diseases, 1970; 15: p. 617-25.

8. Rajbhandari M, Karmacharya A, Khanal K, Dhakal P, Shrestha R. Histomorphological profile of colonoscopic biopsies and pattern of colorectal carcinoma in Kavre district. Kathmandu Univ Med J (KUMJ), 2013;11(43):196-200. Website

9. Holzheimer RG, Mannick JA. Surgical Treatment: Evidence-Based and Problem-Oriented, 2001. Website 
10. Lee BG, Shin SH, Lee YA, Wi JH, Lee YJ, Park JH. Juvenile polyp and colonoscopic polypectomy in childhood. Pediatr Gastroenterol Hepatol Nutr, 2012;15(4):250-5. Crossref

11. Corley DA, Jensen CD, Marks AR, et al., Variation of adenoma prevalence by age, sex, race, and colon location in a large population: implications for screening and quality programs. Clin Gastroenterol Hepatol, 2013. 11(2): p. 172-80. Crossref

12. Hussain M, Khalid AB, Ahsan S, et al., Age and site of Colonic Neoplastic Lesions: Implications of screening in South Asia. Pak J Med Sci, 2014. 30:1277-80. Crossref

13. Mohsin-ul-Rasool, Mubeen B, Andrabi RS, Hamid S, Rasool Z, Shah P, Shah OJ. Histopathological study of neoplastic lesions of large intestine in Kashmir Valley, India. Int J Res Med Sci 2014;2:1097100. Crossref
14. Tung SY, CS Wu. Risk factors for colorectal adenomas among immediate family members of patients with colorectal cancer in Taiwan: a case-control study. Am J Gastroenterol, 2000;95:3624-8. Crossref

15. Franklin, R. and B. McSwain, Juvenile polyps of the colon and rectum. Annals of surgery, 1972. 175(6): p. 887-891.

16. Betés M1, Muñoz-Navas MA, Duque JM, et al., Use of colonoscopy as a primary screening test for colorectal cancer in average risk people. Am J Gastroenterol, 2003; 98: 2648-54.

17. Eshghi MJ, Fatemi R, Hashemy A, Aldulaimi D, Khodadoostan M. A retrospective study of patients with colorectal polyps. Gastroenterol Hepatol Bed Bench. 2011; 4: 17-22. PMC4017400

18. Tam B, Salamon A, Bajtai A, et al., The real face of juvenile polyposis syndrome. J J Gastrointest Oncol., 2012. 3(4):362-8. Crossref 